
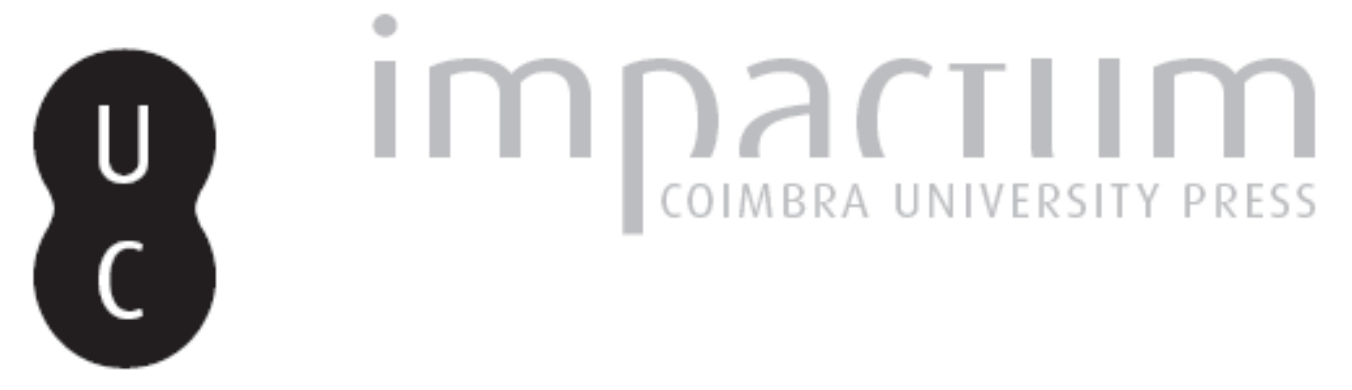

\title{
Planeamento, turismo e património em territórios de baixa densidade
}

Autor(es): $\quad$ Carvalho, Paulo

Publicado por: Faculdade de Letras da Universidade de Coimbra

URL persistente:

URI:http://hdl.handle.net/10316.2/32770

DOI:

DOI:http://dx.doi.org/10.14195/0870-4112_7_22

Accessed : $\quad$ 26-Apr-2023 12:23:38

A navegação consulta e descarregamento dos títulos inseridos nas Bibliotecas Digitais UC Digitalis, UC Pombalina e UC Impactum, pressupõem a aceitação plena e sem reservas dos Termos e Condições de Uso destas Bibliotecas Digitais, disponíveis em https://digitalis.uc.pt/pt-pt/termos.

Conforme exposto nos referidos Termos e Condições de Uso, o descarregamento de títulos de acesso restrito requer uma licença válida de autorização devendo o utilizador aceder ao(s) documento(s) a partir de um endereço de IP da instituição detentora da supramencionada licença.

Ao utilizador é apenas permitido o descarregamento para uso pessoal, pelo que o emprego do(s) título(s) descarregado(s) para outro fim, designadamente comercial, carece de autorização do respetivo autor ou editor da obra.

Na medida em que todas as obras da UC Digitalis se encontram protegidas pelo Código do Direito de Autor e Direitos Conexos e demais legislação aplicável, toda a cópia, parcial ou total, deste documento, nos casos em que é legalmente admitida, deverá conter ou fazer-se acompanhar por este aviso.

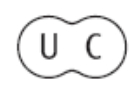




\section{Sociedade em Tumulto}

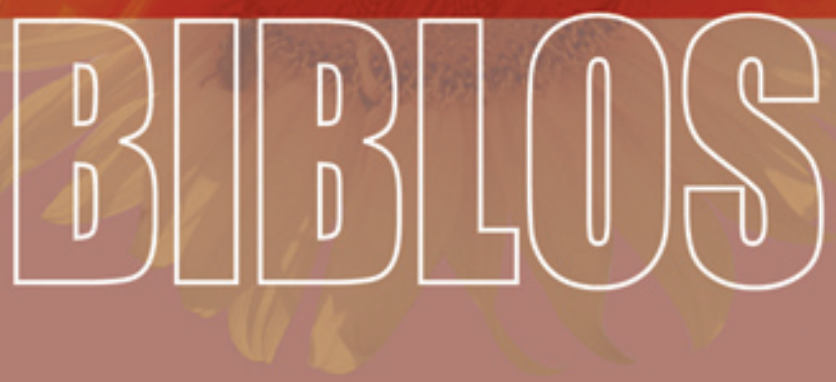

REVISTA DA FACULDADE DE LETRAS

UNIVERSIDADE DE GOIMBRA 
Biblos, n. s. VII (2009) 483-504

Paulo Carvalho

Centro de Estudos de Geografia e Ordenamento do Território (CEGOT)

Universidade de Coimbra

\section{PLANEAMENTO, TURISMO E PATRIMÓNIO EM TERRITÓRIOS DE BAIXA DENSIDADE ${ }^{1}$}

\section{RESUMO}

O planeamento do turismo é uma ferramenta estruturante da política de desenvolvimento sustentável e por isso ocupa um lugar decisivo no processo de concepção e implementação de estratégias de desenvolvimento. No contexto das novas escolhas geográficas do turismo e do lazer, o património natural e cultural é cada vez mais utilizado no âmbito de estratégias de requalificação territorial, revitalização do tecido económico e social, e criação de novos produtos turísticos. A escala e a organização (em rede) da oferta turística, a promoção integrada e a gestão participada são algumas das suas dimensões mais inovadoras.

As "Aldeias do Xisto" (Pinhal Interior/Região Centro de Portugal), exemplo utilizado para aprofundar este quadro conceptual, configuram um projecto inovador que permitiu criar uma rede integrada de entidades públicas e privadas, tendo em vista a afirmação de uma marca diferenciadora no contexto turístico nacional.

Palavras-chave: Planeamento, turismo, património, rede de aldeias do xisto.

\section{Abstract}

Tourism planning is a tool for structuring sustainable development policy, which is why it is so crucial to the process of devising and implementing development strategies. In the context of new geographic choices for tourism and leisure, natural and cultural heritage is being increasingly used in territorial

${ }^{1} \mathrm{O}$ presente texto resulta da nossa participação no $2^{\text {nd }}$ Portuguese-Speaking Congress of Regional Science/ $1^{\text {st }}$ Cape Verde Congress of Regional Development (Praia, Santiago Island, Cape Verde, Jean Piaget University, $6^{\text {th }}$ to $11^{\text {th }}$ July, 2009) e tem como suporte o trabalho publicado no âmbito desse evento, com actualização da informação relativa ao caso de estudo. 
regeneration strategies, in the revitalization of the economic and social fabric and in the creation of new tourist products. The scale and organization (in a network) of tourist supply, integrated promotion and participatory management are just some of its more ground-breaking dimensions.

The example of "Schist Villages" (Pinhal Interior/ Central Region of Portugal) is used to strengthen this conceptual framework. They represent an innovative project for the creation of an integrated network of public and private organizations that aims to be a distinguishing feature in the Portuguese tourist landscape.

Keywords: Planning, tourism, heritage, schist villages network.

\section{Planeamento, turismo e sustentabilidade}

A importância crescente da dimensão territorial no quadro das políticas públicas e o seu reconhecimento como eixo vertebrador do desenvolvimento sustentável contribuíram para repensar o valor estratégico do planeamento em diversas actividades alicerçadas na utilização de recursos finitos e, em alguns casos, não renováveis, como é o caso do turismo. A dimensão espacial do turismo e em particular as suas externalidades negativas conduziram ao reconhecimento da necessidade de repensar a actividade turística segundo uma óptica alicerçada na relação qualidade/continuidade. $\mathrm{O}$ forte crescimento do número de turistas (nacionais e internacionais) e a expressão urbanística do lazer e do turismo são outros argumentos de peso que justificam as preocupações actuais em matéria de sustentabilidade e planeamento da actividade turística. Assumindo o planeamento como uma ferramenta indispensável das políticas de promoção do desenvolvimento sustentável, podemos afirmar que a transposição dos seus princípios nucleares para o campo do turismo pretende, no essencial, salvaguardar recursos, criar e distribuir benefícios, e envolver as populações locais. Planear o turismo é uma condição necessária para a organização, a viabilidade e a sustentabilidade da própria actividade, e a sua evolução em harmonia com os pilares do desenvolvimento sustentável designadamente as vertentes económica, social, cultural e ambiental ${ }^{2}$.

${ }^{2}$ P. Carvalho, "Planeamento, Redes Territoriais e Novos Produtos Turísticos Eco-culturais", Actas do $2^{\circ}$ Congresso Regional de Ciência Regional/1 ${ }^{\circ}$ Congresso de Desenvolvimento Regional de Cabo Verde, Associação Portuguesa para o Desenvolvimento Regional, 2009 (edição em CD-ROM). 
A evolução do conceito de desenvolvimento influenciou de forma decisiva o caminho do processo de planeamento e a sua aplicação no âmbito do turismo. O final dos anos 60 e o início da década de 70 do século passado são marcados por alterações na concepção e na prática do planeamento associadas a importantes transformações nas formas de intervenção dos Estados (descentralização, novos níveis de planeamento sectoriais e espaciais, criados para enquadrar diferentes formas de governo local e regional), e ao problema decorrente da crise financeira do Estado que se reflectiu em novas prioridades nas despesas públicas ${ }^{3}$.

Nessa fase, em que planeamento regional e urbano é o rosto de maior visibilidade das políticas públicas, dominam as preocupações de natureza económica e as orientações ambientais primam ainda pela ausência. $\mathrm{O}$ crescimento do turismo e a crescente capacidade de gerar lucros justificam a importância do planeamento turístico, domínio que assumirá "ênfase fundamentalmente a partir da década de 80 ".

Ao mesmo tempo, emerge o planeamento estratégico, como resultado da necessidade de intervir globalmente sobre o quadro sócioeconómico do desenvolvimento (urbano) e de melhorar a eficácia dessas intervenções, garantindo a articulação e cooperação entre os actores desse desenvolvimento. O objectivo é ultrapassar as insuficiências e as dificuldades dos sistemas de planificação tradicional (resultantes do crescimento urbano do pós-guerra), uma vez que estas regulamentam muito mais que estimulam; concentram o papel de motor e o poder de decisão mais do que repartem a responsabilidade na iniciativa e no consenso; privilegiam a alteração das estruturas edificadas; não são plataformas dinamizadoras de acções a empreender de forma conjunta ${ }^{5}$, e não configuram o planeamento como um processo dinâmico, "que define os objectivos e o caminho para os alcançar, num contexto de constante avaliação, que permite reagir, atempadamente, às mudanças

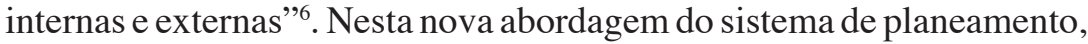

${ }^{3}$ Direcção Geral de Ordenamento do Território e Desenvolvimento Urbano (DGOTDU), Guia para Elaboração de Planos Estratégicos de Cidades Médias, Lisboa, DGOTDU, 1996.

${ }^{4}$ C. Henriques, Turismo, Cidade e Cultura. Planeamento e Gestão Sustentável, Lisboa, Edições Sílabo, 2003.

${ }^{5}$ J. Borja y M. Castells, Local y Global. La Gestión de las Ciudades en la Era de la Información, Madrid, Taurus, 2000.

${ }^{6}$ M. Brito e C. Silva, "Turismo e Planeamento: A Continuidade ou a AutoDestruição”, Revista Turismo \& Desenvolvimento, vol. II (2), 2005, pp. 11-24. 
importa entender e actuar sobre as condições sociais e económicas do desenvolvimento e não apenas sobre as suas consequências, bem como criar condições para promover o desenvolvimento segundo princípios de cultura de transformação urbana e de desenvolvimento sustentável.

Assim, um plano estratégico é a definição de um projecto de incidência espacial que unifica diagnósticos, combina e concretiza acções públicas e privadas e estabelece um quadro de mobilização e de cooperação dos actores sociais. Trata-se, fundamentalmente, de um instrumento de apoio à tomada de decisões e ao mesmo tempo, uma proposta de responsabilidade partilhada que coloca grandes desafios para a modernização do território e a melhoria da qualidade de vida dos cidadãos. As propostas de acção, na sequência de uma análise de oportunidades, representam uma base de trabalho para o diálogo e a contratualização.

É reconhecido pela comunidade científica que os sistemas de ordenamento do território, considerados essenciais para a execução das políticas de desenvolvimento sustentável, deverão ser consolidados, encorajando abordagens de inspiração ecológica e o abandono de sistemas rígidos na afectação do solo. Ao mesmo tempo, importa que os modelos de planeamento top down tradicionais incorporem os interesses da comunidade local no processo de decisão e de planeamento e se constituam como bottom-up ${ }^{7}$. A utilização de metas e indicadores, o melhoramento dos sistemas de participação pública no planeamento e a ligação potencial entre o ordenamento do território e os processos da Agenda 21, marcam uma nova etapa nos processos de ordenamento e gestão do território ${ }^{8}$.

Face ao exposto, as novas orientações teóricas e metodológicas do planeamento aplicadas ao turismo enfatizam o desenvolvimento sustentável da actividade turística. A Organização Mundial do Turismo9, inspirada no relatório da World Commission on Environment and Development ${ }^{10}$, também conhecido como "Relatório Brundtland", e em

${ }^{7}$ C. Henriques, op. cit.

${ }^{8} \mathrm{P}$. Carvalho, "Turismo cultural, património e políticas públicas em contextos rurais de baixa densidade", in G. Santos et al. (eds.), Actas do Congresso de Turismo Cultural, Território e Identidades, Leiria, Instituto Politécnico de Leiria, 2006.

${ }^{9}$ World Tourism Organization (WTO), Tourism Development and the Responsability of the State. Seminary on Tourism Development and the Responsability of the State, Budapest, World Tourism Organization, 1993.

${ }^{10}$ World Commission on Environment and Development (WCED), Brundtland Report, WCED, 1987. 
outros contributos afins, define turismo sustentável como uma prática responsável, que visa satisfazer a procura turística (os interesses dos visitantes), capaz de conciliar a preocupação com a salvaguarda e a valorização dos recursos turísticos (fundamentos da oferta turística), e aumentar os benefícios destes recursos para a população local.HENRIQUES $^{11}$, a respeito da consolidação do turismo sustentável, como uma ferramenta básica de gestão dos recursos turísticos, sublinha a importância da aplicação dos princípios de desenvolvimento sustentável ao turismo, nomeadamente a equidade, a preocupação com o longo prazo, a capacidade de carga, a conservação e as parcerias.

Apesar do descompasso entre as dinâmicas territoriais do turismo e as preocupações efectivas/acções concretas em matéria de planeamento desta actividade, não restam dúvidas de que o planeamento do turismo sustentável deve contribuir para promover "um turismo soft, qualitativo, alternativo e responsável, que pressupõe uma visão administrativa moderna, com uma rendibilidade moderada, mas contínua no tempo, e com uma postura responsável face à envolvente social, ambiental e cultural", assimcomo "deverá constituiruma plataforma de entendimento e de harmonização entre os objectivos e as necessidades de todos os interventores no processo (...), num contexto de desenvolvimento sustentável" 12 .

A articulação entre o planeamento e o desenvolvimento turístico (ou do turismo) sustentável, tendo em vista satisfazer as necessidades económicas, sociais e estéticas sem colocar em causa a continuidade dos recursos turísticos (designadamente culturais e ecológicos), remete para a relevância do próprio processo de planeamento (definição de objectivos, análise e diagnóstico; formulação de propostas; decisão; monitorização; avaliação). Como refere $\mathrm{BRITO}^{13}$, "a operacionalização do conceito de turismo sustentável começa na fase de planeamento, não só nos resultados deste processo, mas também na forma como ele próprio se desenrola. Neste campo, a inovação tem-se feito sentir, porque a própria necessidade de garantir a competitividade dos destinos tem aberto as portas à criatividade e à vontade de implementar modelos de planeamento que conduzam à continuidade numa perspectiva de qualidade".
${ }^{11}$ C. Henriques, op. cit.
${ }^{12} \mathrm{M}$. Brito e C. Silva, op. cit.
${ }^{13}$ M. Brito, Planear para o turismo sustentável: prova(s) da sua exequibilidade, Coimbra, 2009, p. 3 (inédito). 
INSKEEP $^{14}$, HALL $^{15}$, PAGE e HALL ${ }^{16}$, BURNS ${ }^{17}$, entre outras referências, a respeito de planear o turismo e definir modelos de planeamento turístico, recomendam mudanças no processo de planeamento, desde logo por via da decisão inequívoca de planificar (visão política), assim como enfatizam o relacionamento institucional, a interacção entre os actores, o envolvimento das comunidades locais, e as componentes de monitorização e avaliação da sustentabilidade dos destinos turísticos - estas últimas referidas, também, por PARTIDÁ$\mathrm{RIO}^{18}$, BAUMGARTNER ${ }^{19}$ e CARETO ${ }^{20}$. O reconhecimento da validade das boas práticas em planeamento e desenvolvimento turístico, ou seja, exemplos de experiências positivas para os destinos turísticos e para as comunidades locais, é mais um contributo inovador e uma ferramenta válida neste domínio.

Em síntese, a visão actual do planeamento turístico configura uma plataforma de geometria variável, uma vez que o planeamento da actividade turística "ocorre sob uma variedade de formas (desenvolvimento, infra-estruturas, uso do solo e dos recursos, organização, recursos humanos, promoção e marketing), estruturas (diferentes governos, organizações quase e não governamentais), escalas (internacional, transnacional, regional, local, de lugar) e em diferentes tempos (para desenvolvimento, implementação, avaliação, e o atingir satisfatório dos objectivos de planeamento" ${ }^{21}$.

${ }^{14}$ E. Inskeep, Tourism Planning. An integrated and Sustainable Development Approach, New York, Van Nostrand Reinhold, 1991.

15 C. Hall, Tourism Planning. Policies, Process and Relationships, Harlow, Prentice Hall, 2000.

${ }^{16}$ S. Page and C. Hall, Managing Urban Tourism, London, Prentice Hall, 2003.

${ }^{17}$ P. M. Burns, "Tourism Planning - A Third Way?", Annals of Tourism Research, 30(1), 2004, pp. 24-43.

${ }^{18}$ M. R. Partidário, "O ambiente como factor de competitividade no turismo", in H. Careto e S. Lima (coords.), Turismo e Desenvolvimento Sustentável - 1, Lisboa, GEOTA, 2006, pp. 71-74.

${ }^{19}$ C. Baumgartner, "A avaliação da sustentabilidade dos destinos turísticos", in H. Careto e S. Lima (coords.), Turismo e Desenvolvimento Sustentável - 1, Lisboa, GEOTA, 2006, pp. 81-91.

${ }^{20} \mathrm{H}$. Careto, "O diagnóstico, a avaliação e os indicadores ambientais", in $\mathrm{H}$. Careto e S. Lima (coords.), Turismo e Desenvolvimento Sustentável - 1. Lisboa, GEOTA, 2006, pp. 75-80.

${ }^{21} \mathrm{C}$. Henriques, op. cit.

Faculdade de Letras | Universidade de Coimbra 


\section{Planeamento e desenvolvimento de novos produtos turísticos associados ao património natural e cultural, em territórios de baixa densidade}

As tendências actuais em matéria de oferta e procura turística demonstram a relevância de produtos que configuram novas escolhas geográficas como, por exemplo, o campo, os planos de água e a montanha. No caso de Portugal, estas escolhas geográficas (alternativas) representam cerca de $20 \%$ das respostas sobre o ambiente de gozo de férias, de acordo com as estatísticas sobre as Férias dos Portugueses, da Direcção Geral do Turismo ${ }^{22}$. Esta situação decorre, entre outros factores, das mudanças qualitativas que marcam o (novo) comportamento dos turistas. De facto, neste início de milénio os turistas são mais activos e participativos; têm interesses mais diversificados e segmentados ${ }^{23}$; são mais exigentes e menos influenciados pelas perspectivas da oferta massificada ${ }^{24}$; estão mais esclarecidos e informados ${ }^{25}$.

A acção pública nacional em matéria de política e instrumentos de promoção do desenvolvimento, considerando o referido contexto geográfico (territórios de baixa densidade) e a política regional europeia, apresenta como principais dimensões inovadoras a valorização dos contextos territoriais e dos recursos endógenos, a definição de escalas e a formatação de espaços de planeamento e intervenção, e a construção de redes territoriais, apesar das insuficiências reconhecidas no âmbito da articulação das políticas sectoriais e da divulgação e utilização adequada das ferramentas/resultados dos processos de acompanhamento e avaliação das iniciativas.

O espectro das intervenções em Portugal, com especial incidência no período correspondente ao $3^{\circ}$ Quadro Comunitário de Apoio (20002006), permite fixar exemplos em diversas regiões, como as Aldeias Vinhateiras do Douro (Norte), as Aldeias Históricas de Portugal

22 Direcção Geral do Turismo, Férias dos Portugueses: Março 2006, Lisboa, DGT, 2007.

${ }^{23}$ World Tourism Organization (WTO), 2003.

${ }^{24} \mathrm{~J}$. C. Barros, A projecção do quotidiano no turismo e no lazer, Lisboa, ISCSP/ UTL, 2004.

${ }^{25}$ F. Mcgettigan, "Uma Análise do Turismo Cultural e a sua relação com Lugares de Peregrinação", in Instituto de Turismo de Portugal (ed.), Novos Consumos. Novos Produtos Encontro Técnico 2003. Livro de Actas, Lisboa, Instituto de Turismo de Portugal, 2005, pp.127-146. 
(Centro), as Aldeias do Xisto (Centro), as Aldeias de Água (Alentejo), as Aldeias com Castelo e Património (Alentejo), as Aldeias de Mina (Alentejo), as Aldeias do Algarve (Algarve), entre outras. Duas particularidades podem ser identificadas como traços comuns a (quase todas) estas iniciativas: a sua inclusão em acções integradas de base territorial (no caso das Aldeias Históricas, a referida acção integrada configura uma segunda fase de intervenção, uma vez que a iniciativa começou no anterior período de programação das políticas públicas, ou seja, em 1994-1999) e o propósito de transformar programas de requalificação e revitalização (desenvolvimento) em redes territoriais (funcionais).

\subsection{Aldeias do Xisto: requalificar/revitalizar microterritórios e induzir novas centralidades no âmbito do lazer e da oferta turística}

O Programa das Aldeias do Xisto (PAX) é uma iniciativa pública de desenvolvimento suportada pela Acção Integrada de Base Territorial (AIBT) do Pinhal Interior (Componente FEDER), do Eixo II (Acções Integradas de Base Territorial) do Programa Operacional da Região Centro (2000-2006), que pretendeu requalificar "um conjunto de aldeias serranas (recuperação de coberturas e fachadas, requalificação de espaços sociais, instalação de mobiliário urbano, recuperação de pavimentos de ruas e calçadas, infra-estruturação com redes básicas)" e constituir "uma rede de sítios de interesse turístico"26.

A estruturação e a implementação da AIBT do Pinhal Interior, a partir da análise dos seus principais domínios de intervenção e investimentos realizados, reflectem dois eixos prioritários: o turismo (cultural e ecológico) e o património (cultural e natural ${ }^{27}$. Segundo elementos relativos a Janeiro de 2006, o investimento total aprovado aproximava-se de 25 milhões de euros, destacando-se o PAX (com 10.63 milhões de euros e $44.8 \%$ do investimento) e as iniciativas de valorização do património natural e cultural (entre as mais importantes neste domínio), com 52\% do investimento aprovado (12.36 milhões de

${ }^{26}$ Comissão de Coordenação da Região Centro, Programa Operacional da Região Centro: 2000-2006, Coimbra, CCRC, 2001.

${ }^{27}$ P. Carvalho, "Património cultural, ordenamento e desenvolvimento: uma nova visão e valorização do território", Cadernos de Geografia, no 24/25, 2008, pp. 209-226. 
euros). Os projectos aprovados neste último contexto cobrem diversas áreas como, por exemplo, as praias fluviais e os museus ${ }^{28}$. A título de comparação, podemos referir que as Aldeias Históricas de Portugal, no período de 1994 até 2002 (primeiro, em 1994-1999, como Programa Nacional, abrangendo dez lugares, e depois, em 2000-2006, como AIBT do Programa Operacional da Região Centro, integrando mais dois lugares), apoiaram investimentos (concretizados) de cerca de 35 milhões de euros (montante que, entretanto, ultrapassou os 40 milhões de euros). Por outro lado, é importante referir outras linhas de acção concretizadas, como a reabilitação social, em que foram realizadas diversas acções de formação dirigidas às populações das Aldeias do Xisto no sentido de dotá-las com as competências básicas em diversas áreas, designadamente atendimento turístico, pedreiros do xisto e gastronomia ${ }^{29}$, e o apoio às actividades económicas relacionadas com o turismo, nomeadamente alojamento, animação, restauração/cafetaria e comércio de produtos endógenos.

\subsubsection{Planos de Aldeia e requalificação territorial}

No âmbito do PAX, a selecção dos lugares teve como suporte a avaliação das candidaturas apresentadas pelos municípios (através de um Plano de Aldeia, para cada lugar). O Plano de Aldeia configura um instrumento de gestão territorial (com semelhanças em relação aos Planos de Pormenor) tendo em vista definir propostas/linhas de acções em matéria de intervenção física (figura 1), na sequência de uma análise e diagnóstico de cada lugar. Este processo permitiu fixar um conjunto de micro-territórios que têm em comum traços inequívocos resultantes de trajectórias de abandono e progressiva desvitalização demográfica, económica e social, não obstante as especificidades territoriais que decorrem de indicadores como os estatutos de protecção das paisagens, as características demográficas, económicas e sociais, e as estruturas edificadas, designadamente o número de imóveis, o estado de conservação, as características arquitectónicas, e a tipologia de ocupação ${ }^{30}$.

${ }^{28}$ P. Carvalho, "Turismo cultural, património e políticas públicas em contextos rurais de baixa densidade", in G. Santos et al. (eds.), Actas do Congresso de Turismo Cultural, Território e Identidades, Leiria, Instituto Politécnico de Leiria, 2006.

${ }^{29}$ A. Carvalho, "Programa das Aldeias do Xisto: caminhos para o Turismo de Natureza", Revista Turismo \& Desenvolvimento, $\mathrm{n}^{\circ}$ 6, 2006, pp. 27-30.

${ }^{30} \mathrm{P}$. Carvalho, op. cit. 
A elaboração dos Planos de Aldeia e a sua implementação territorial decorreu no contexto dos GAT (Gabinetes de Apoio Técnico), dos GTL (Gabinetes Técnicos Locais) e contou com a colaboração de algumas empresas particulares de prestação de serviços na área do planeamento (em casos pontuais).

Os vinte e quatro lugares seleccionados para o PAX (23, seleccionados até 2003, e mais um, integrado na fase final do Programa) encontram-se repartidos por catorze municípios das sub-regiões do Pinhal Interior Norte, Pinhal Interior Sul, Beira Interior Sul e Cova da Beira. A geografia do PAX é marcada por dois subconjuntos principais: o agrupamento de lugares da Serra da Lousã e da sua bordadura sudoeste (que perfazem mais de 50\% do Programa), e o alinhamento de aldeias na proximidade do Médio Zêzere, cuja articulação com a região e o país decorre da utilização de três portas de acesso principais: a Serra da Lousã (por via das estradas nacionais $\mathrm{n}^{\circ} 2,17-1,236,342$, e do itinerário complementar $\mathrm{n}^{\circ} 3$ ), o itinerário complementar $\mathrm{n}^{\circ} 8$ (IC8) e a auto-estrada $\mathrm{n}^{\circ} 23(\mathrm{~A} 23)$.

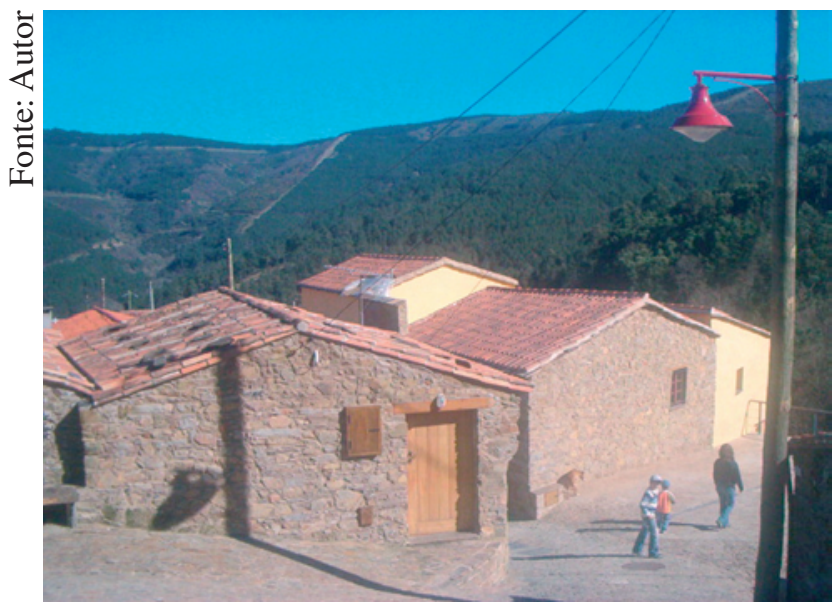

Figura 1. Imóveis particulares recuperados e espaços públicos requalificados no âmbito do PAX, em Gondramaz (Miranda do Corvo, 2008)

A análise da distribuição do investimento aprovado no âmbito do PAX, segundo as categorias de intervenção e os territórios envolvidos, 
com base em resultados publicados no âmbito das nossas investigações ${ }^{31}$, permitiu fixar as seguintes conclusões:

- De modo individual, destacam-se os imóveis particulares (37.5\% do investimento aprovado), os espaços públicos (19.7\%), as infra-estruturas (10.9\%) e estas duas últimas componentes de forma agrupada (13.2\%); a intervenção nos espaços públicos foi responsável por $10.2 \%$ do investimento aprovado.

- As câmaras municipais são o maior investidor do PAX; esta evidência é reforçada pelo facto de o esforço de investimento das autarquias ser mais elevado, em face da menor taxa de compartição do Estado e da União Europeia para os domínios de intervenção em causa (espaços públicos e infra-estruturas básicas).

- A distribuição do investimento aprovado é desigual segundo os lugares, repartindo-se no intervalo de variação de 152 mil (Casal de São Simão) a 1.2 milhões de euros (Janeiro de Cima). De igual modo, as diferenças de investimento aprovado no plano municipal são muito marcadas: entre 152 mil euros (Figueiró dos Vinhos) e 1.7 milhões de euros (Fundão).

No início de 2006 estavam aprovadas 424 intervenções em imóveis particulares, 34 intervenções em imóveis públicos, 47 acções em espaços públicos e cerca de 30 acções relacionadas com infraestruturas ${ }^{32}$.

\subsubsection{Criar um novo destino/produto turístico, inventar uma marca e promover um território}

A implementação dos Planos de Aldeia, por via da requalificação territorial dos lugares serranos, contribuiu para melhorar a qualidade de vida das populações locais e assegurou um conjunto de condições fundamentais que permitiram lançar as bases de um produto turístico vocacionado para os segmentos da procura turística relacionados com o turismo cultural, o turismo de natureza, o turismo de aldeia e o turismo activo. A integração das Aldeias do Xisto na geografia dos destinos turísticos e do lazer deve ser entendida de acordo com a amplitude das novas motivações turísticas e de lazer, nomeadamente a aquisição de habitação secundária, o retorno às origens, a aquisição de produtos endógenos, a procura de paisagens de elevada qualidade estética e

\footnotetext{
${ }^{31}$ Idem, ibidem.

${ }^{32}$ Idem, ibidem.
} 
ambiental, a valorização do património natural e cultural, o desejo de viver novas experiências e a prática de actividades ao ar livre.

A prossecução deste objectivo, ainda na vigência da AIBT do Pinhal Interior, decorreu no contexto de duas iniciativas muito relevantes.

Por um lado, a criação de um Sistema de Incentivos Específicos para o Pinhal Interior (SIEPI), responsável por 3.2\% do total de investimento elegível aprovado no âmbito da referida AIBT ${ }^{33}$, apoiou a instalação ou o reforço de iniciativas de investimento empresarial nas áreas do alojamento turístico (em unidades de turismo em espaço rural - figura 2), animação turística, restauração, comércio e divulgação de produtos locais (em particular o artesanato). De forma complementar, a capacidade de alojamento turístico do contexto geográfico (escala municipal) das Aldeias do Xisto ${ }^{34}$, foi ampliada, diversificada e qualificada, através da concretização de importantes projectos, com o apoio de outros programas como, por exemplo, o LEADER+ (Ligação Entre Acções de Desenvolvimento da Economia Rural) e o PRIME (Programa de Incentivos à Modernização da Economia) - este último através do SIVITUR (Sistema de Incentivos a Produtos Turísticos de Vocação Estratégica) e do SIPIE (Sistema de Incentivos a Pequenas Iniciativas Empresariais).

${ }^{33}$ Idem, ibidem.

${ }^{34}$ A Pousada das Amoras (integrada nas Pousadas de Portugal), em Proença-aNova, e o Mélia Palácio da Lousã, no centro histórico da Lousã, são dois exemplos emblemáticos de alojamento de qualidade, a partir da recuperação de imóveis de grande valor patrimonial, cuja concretização envolveu a participação activa dos respectivos municípios. A primeira, inaugurada em Dezembro de 2003, oferece 32 quartos e uma suite, e dispõe ainda de restaurante, bar, piscina no exterior, estacionamento, loja de artesanato, sala de reuniões, tenda de eventos e SPA. O segundo, inaugurado em Abril de 2005, de quatro estrelas, oferece quase cinco dezenas de quartos, repartidos por duas alas (nova e antiga) do edifício. Esta unidade hoteleira, o primeiro Mélia Boutique Hotel a abrir em Portugal, oferece ainda serviços de bar e restauração, abertos a toda a população, e dispõe de parque infantil, estacionamento e um auditório (para eventos culturais e científicos). 


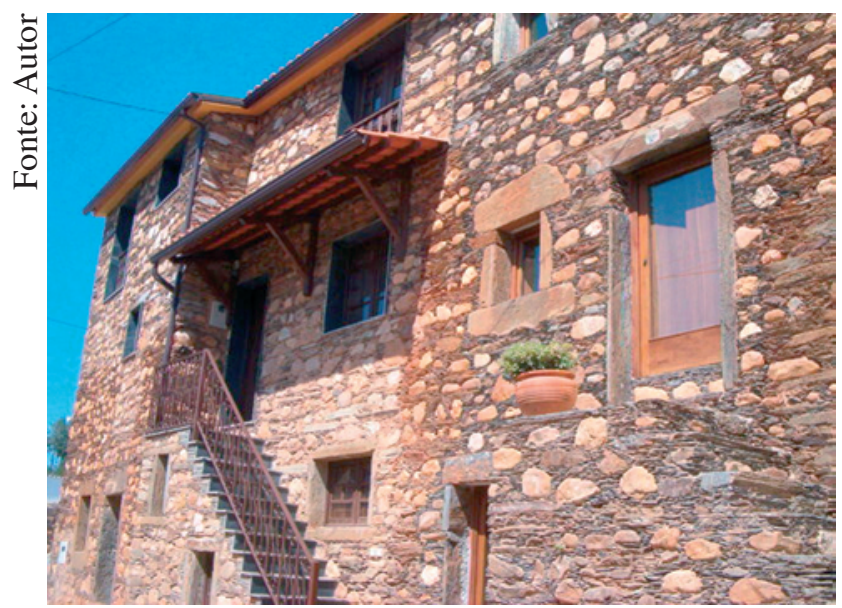

Figura 2. Imóvel particular recuperado, com apoio do PAX, destinado a alojamento turístico, em Janeiro de Cima (Fundão, 2006)

Por outro lado, a elaboração do Plano Global de Desenvolvimento Sustentado das Aldeias do Xisto, preparado e promovido pela Pinus Verde (Associação de Desenvolvimento, com sede no Fundão), através de uma parceria com diversos municípios, entidades institucionais e agentes económicos e culturais da região, com o apoio da Comissão de Coordenação e Desenvolvimento Regional do Centro. Este instrumento orientador definiu como prioritários os seguintes eixos de intervenção:

- Imagem e marketing territorial (conceber e promover uma imagem/marca que identifique e promova o território).

- Comunicação e informação aos visitantes (editar uma revista de divulgação ${ }^{35}$; colocar placares informativos das aldeias e da

${ }^{35}$ A revista "Aldeias do Xisto" é marcada por duas fases editoriais distintas. A primeira edição, de distribuição gratuita, foi lançada pela Comissão de Coordenação e Desenvolvimento Regional do Centro (através da AIBT do Pinhal Interior), entre 2003 e 2004, para dar conta do PAX e das suas realizações (configurando um instrumento de acompanhamento do PAX). A segunda edição, desde os finais de 2005, com a chancela da Pinus Verde, pretende constituir (mais) um meio de atrair visitantes às Aldeias do Xisto. Esta nova edição, com objectivos comerciais, definiu com metas a frequência de publicação quadrimestral, uma tiragem de 6000 exemplares, a distribuição por todos os postos de turismo dos municípios abrangidos, bem como nos postos de turismo de Coimbra e Tomar, a entrega a todos os agentes económicos 
rede em cada aldeia, e inserir sinalética direccional na rede viária).

- Novas funcionalidades económicas, designadamente estabelecer uma rede de lojas (Lojas Aldeias do Xisto) em regime de franchising, tendo em vista comercializar produtos das Aldeias do Xisto como, por exemplo, peças artísticas em porcelana e em madeira (figura 3), bijutaria, joalharia, artigos em pasta de papel, linho, bordados, brinquedos, doces, licores, ervas aromáticas e chás de produção biológica, recomendados com um selo que pretende reconhecer a sua qualidade. De igual modo, está em expansão a criação de produtos de marca, "que vai desde o merchandising de loja às $t$-shirts serigrafadas à mão e de edição limitada, aos blocos de encadernação manual, a cosmética e porcelanas, sempre com motivos inspirados no dia-a-dia das aldeias, tal como ele é vívido hoje" ${ }^{36}$. Depois da primeira loja, que abriu em Lisboa (na Costa do Castelo), em Agosto de 2006, foram inauguradas novas lojas em Aigra Nova (Góis), Candal (Lousã), Barroca (Fundão), Pedrógão Pequeno (Sertã), Martim Branco (Castelo Branco), Fajão (Pampilhosa da Serra), Benfeita (Arganil), Álvaro (Oleiros), Figueira (Proença-a-Nova) e Casal de São Simão (Figueiró dos Vinhos). Neste momento, 10 dos 14 municípios envolvidos no PAX têm lojas Aldeias do Xisto abertas ao público.

- Gestão e promoção das Aldeias do Xisto e dos produtos (turísticos) associados, através da criação de uma Agência para o Desenvolvimento Turístico das Aldeias do Xisto.

- Elaboração e implementação de um Plano de Animação Turística das Aldeias do Xisto.

(alojamento, restauração e animação turística) para assim chegar aos seus clientes, e a distribuição por direct mail para uma lista de cerca de mil opinion makers, entidades públicas e comunicação social, conforme informação divulgada através da página WEB das Aldeias do Xisto.

${ }^{36}$ Revista Aldeias do Xisto, no 4, série II, Fundão, ADXTUR, 2009, p. 51. 


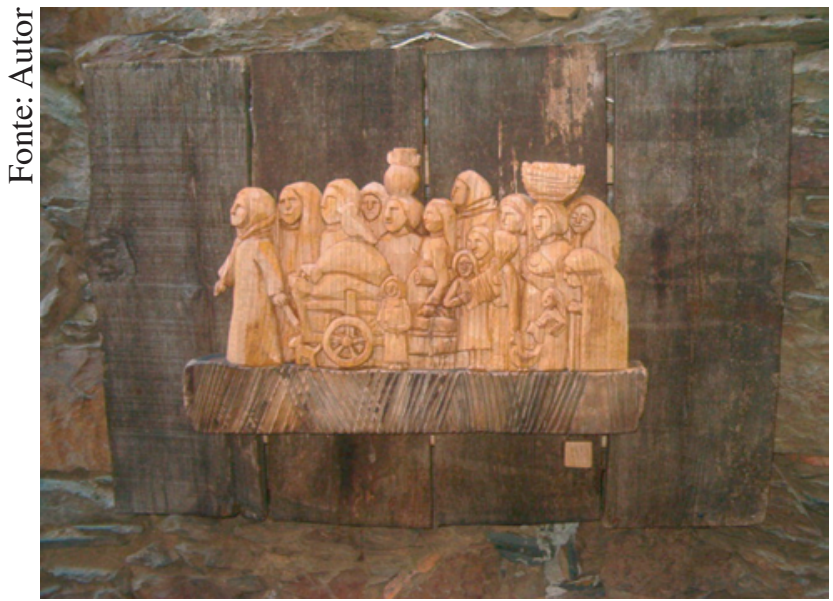

Figura 3. Escultura em madeira, de Kerstin Thomas (Cerdeira, 2008)

\subsubsection{A ADXTUR e a Rede das Aldeias do Xisto}

Para concretizar este último desígnio, afirmar as Aldeias do Xisto como um produto turístico destinado a captar um segmento de mercado muito exigente (ao nível qualidade do serviço, da oferta cultural, da informação disponível e prestada, entre outros) e potenciar paisagens que oferecem inúmeras possibilidades de lazer, revelou-se fundamental a criação da Agência para o Desenvolvimento Turístico das Aldeias do Xisto (ADXTUR).

A ADXTUR (entidade privada sem fins lucrativos), através de uma parceria que envolve 16 municípios e mais de 70 operadores privados que actuam no território, constitui uma plataforma de cooperação muito relevante no percurso de afirmação das Aldeias do Xisto. A oferta de serviços e produtos turísticos dos seus associados (alojamento, restauração, animação turística e comércio tradicional), articulada com o calendário de animação das Aldeias do Xisto, é uma das faces de maior visibilidade da acção inovadora deste órgão colegial, tendo em vista gerir e promover a marca Aldeias do Xisto, articular entidades públicas e agentes privados, induzir dinâmicas locais de desenvolvimento sustentável (através da diversificação e dinamização das actividades económicas, especialmente na área do turismo), valorizar recursos endógenos e contribuir para a integração do Pinhal Interior (na versão da AIBT) nas dinâmicas emergentes do mercado turístico. 
O modelo de gestão da ADXTUR está alicerçado em grupos de trabalho sectoriais, tais como: praias fluviais (Rede de Praias Fluviais Aldeias do Xisto); ambiente, caça e pesca; ordenamento do território e regulamentos urbanos; produtos turísticos; Rede de Lojas Aldeias do Xisto; formação e qualidade - certificação; comunicação e marketing; projectos de desenvolvimento e cooperação estratégica, que correspondem aos eixos estratégicos de acção da Agência.

A presença das Aldeias do Xisto em diversos eventos nacionais (como, por exemplo, a Bolsa de Turismo de Lisboa, desde 2006) e internacionais (como aconteceu na Feira Internacional de Turismo de Berlim, entre 10 e 15 de Março de 2009) demonstra também a sua integração nas estratégias de promoção turística das marcas Centro de Portugal e Portugal.

No plano interno, importa salientar o calendário de animação das Aldeias do Xisto, ou seja, um programa permanente de actividades e eventos idealizados em conjunto com os parceiros locais. O número de iniciativas cifra-se em largas dezenas, de forma continuada e com forte incorporação de inovação, em áreas como a gastronomia, o artesanato, a observação de fauna e de flora, a educação patrimonial, o desporto de natureza e de aventura ${ }^{37}$, a recriação de acontecimentos que compõem o ciclo etnográfico do mundo rural, entre outros.

${ }^{37}$ As características naturais e culturais dos territórios das Aldeias do Xisto configuram cenários paisagísticos de eleição para a realização de provas como o "I Raid Aldeias do Xisto" (uma actividade competitiva de multi-desportos de aventura entre equipas, integrada na Taça de Portugal de Corridas de Aventura), o "I Geo Raid Aldeias do Xisto" (uma prova de resistência em BTT, por algumas das mais emblemáticas Aldeias do Xisto) e o "AX Trail" (uma prova de corrida de montanha de distância reduzida que decorrreu em Casal de São Simão e Ferraria de São João). A “Avalanche” (uma prova de down-hill, em 15 quilómetros de descida e mais de 1000 metros de desnível, desde o Altar do Trevim até à vila da Lousã), com a participação de 500 atletas na última edição (Outubro de 2008), e o "Extreme Riders" (uma prova que decorre em moldes semelhantes em relação à Avalanche), são mais dois exemplos relevantes neste domínio. 
Planeamento, Turismo e Património em Territórios de Baixa Densidade

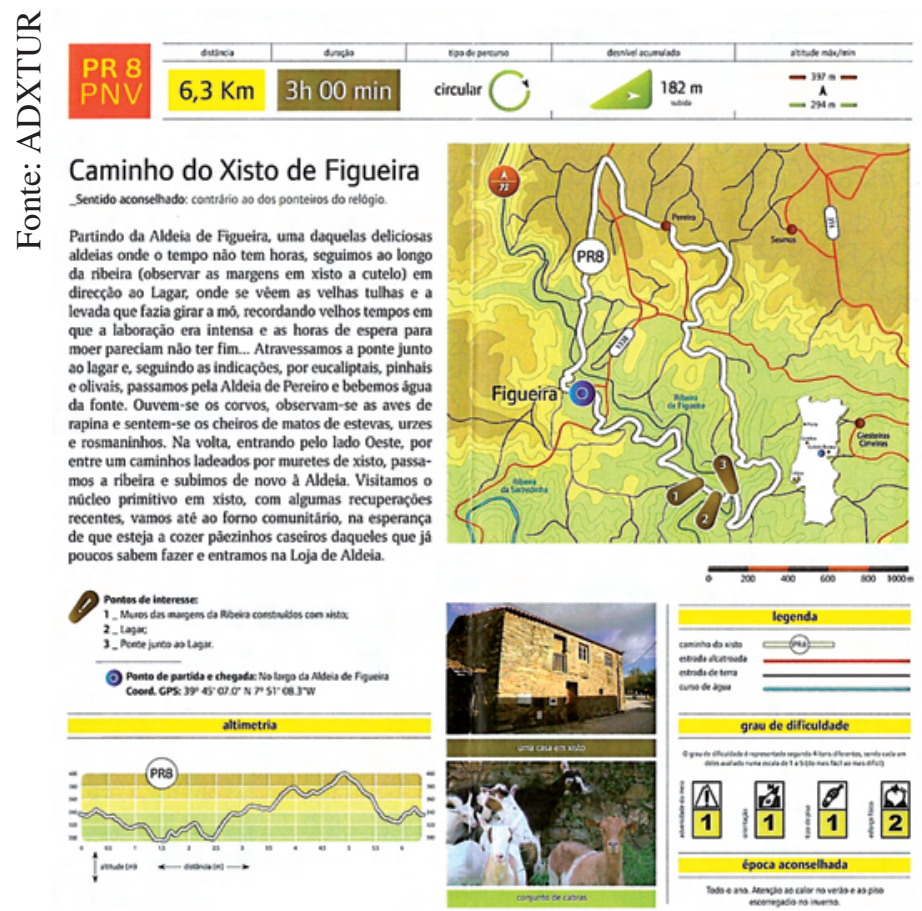

Figura 4. Folheto informativo do Caminho do Xisto de Figueira (Proença-a-Nova, 2009)

As preocupações no que diz respeito ao desporto de natureza, designadamente percursos pedestres e BTT, revelam-se em iniciativas como os Caminhos do Xisto e os Centros de BTT. Os Caminhos do Xisto são percursos pedestres (figura 4) em fase de registo e homologação pela Federação de Campismo e Montanhismo de Portugal, de escala local (pequena rota), como acontece em Água Formosa, Benfeita, Gondramaz (em formato de percurso acessível que permite a sua utilização por cidadãos portadores de incapacidade e com mobilidade condicionada), Fajão, Foz do Cobrão, Góis (Aigra Nova, Aigra Velha, Pena e Comareira), Martim Branco e Lousã (com dois percursos que permitem a ligação entre a vila e o castelo/ermidas, e o castelo/ermidas e a aldeia do Talasnal, respectivamente), ou de escala regional, como acontece com os caminhos da Grande Rota das Aldeias do Xisto (de que é exemplo o troço Ferraria de São João - Casal de São Simão). Os Centros de BTT das Aldeias do Xisto (uma iniciativa inovadora em Portugal), apresentam um conjunto 
de equipamentos para os praticantes desta modalidade (estacionamento, balneários, estação de serviço para bicicletas em regime de self-service - figura 5), associados aos trilhos de BTT (sinalizados e disponíveis ao longo de todo o ano, com diferentes níveis de dificuldade) por entre paisagens de montanha de rara beleza, como acontece na Serra da Lousã (Gondramaz, Ferraria de São João e Lousã).

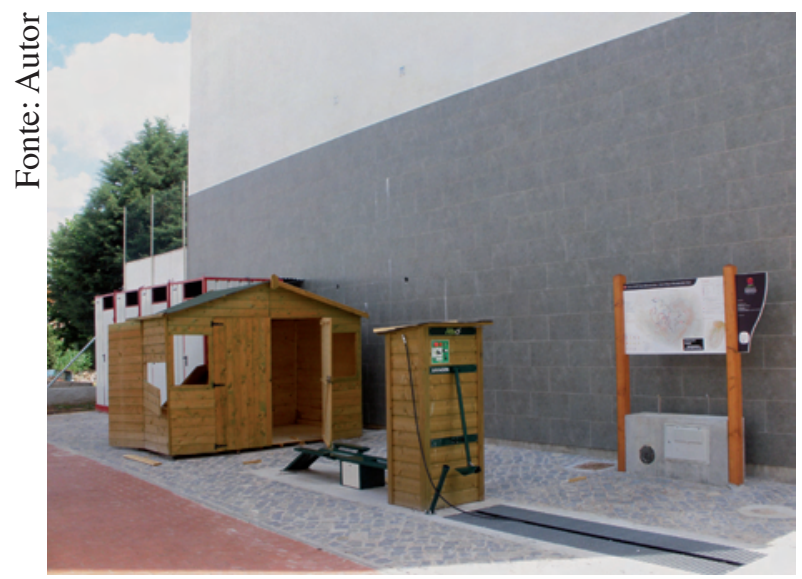

Figura 5. Centro de BTT da Lousã (Junho de 2009)

\subsubsection{Desafios e oportunidades no contexto da nova fase de programação e execução das políticas públicas}

O actual período de programação e execução das políticas públicas (2007-2013) configura novos desafios e abre novas janelas de oportunidade para as Aldeias do Xisto, num cenário de maior exigência em matéria de cooperação, articulação e integração.

O PROVERE (Programa de Valorização Económica de Recursos Endógenos), no âmbito do Quadro de Referência Estratégico Nacional, é um instrumento desenvolvido pelo Ministério do Ambiente, do Ordenamento do Território e do Desenvolvimento Regional que pretende estimular iniciativas de melhoria da competitividade territorial dos territórios de baixa densidade, através de um consórcio formado por entidades públicas e privadas, a partir de recursos singulares como o património natural e o património cultural.

A iniciativa "BuY NATURE - Turismo Sustentável em Áreas Classificadas" é uma das oito candidaturas aprovadas pelo Programa 
Operacional da Região Centro (2007-2013) para as acções preparatórias do PROVERE. Esta iniciativa, coordenada pelo Instituto de Conservação da Natureza e da Biodiversidade (com base numa rede de parceiros públicos e privados dos territórios envolvidos, entre os quais se encontram a Agência para o Desenvolvimento Turístico das Aldeias do Xisto, a Associação das Aldeias Históricas de Portugal e a Naturtejo), pretende potenciar os recursos endógenos do património natural das áreas classificadas de montanha da Região Centro - complementados pelo respectivo património cultural - através da implementação de uma estratégia de base territorial alicerçada no turismo de natureza, no desporto de natureza e no turismo activo, que se afirme como uma iniciativa que reforce a competitividade do território, com características inovadoras e sustentável.

Ainda neste contexto, segundo a página WEB das Aldeias do Xisto, a própria ADXTUR, no passado mês de Janeiro, apresentou uma candidatura ao PROVERE através de uma parceria com mais de 160 entidades territoriais (de 24 municípios). Esta proposta, para o período 2009-2012, representa um investimento de quase 150 milhões de euros (cerca de $70 \%$ do qual corresponde aos agentes privados), e apresenta como eixos de acção, a regeneração urbana das aldeias e revitalização do património rural construído; a valorização turística (infra-estruturas e serviços); a animação turística (serviços e infra-estruturas nas Aldeias e noutros contextos geográficos promocionais; o marketing e a comunicação territorial (para afirmar a marca Aldeias do Xisto, enquanto destino turístico de qualidade, no mercado turístico nacional e internacional); a criação de um centro de valorização e de inovação (recursos humanos, empresas e novos produtos); a consolidação da Rede de Lojas Aldeias do Xisto; a gestão e a promoção integrada da Rede de Praias Fluviais Aldeias do Xisto; a valorização ambiental dos recursos naturais; a requalificação do tecido urbano das vilas sede de concelho das Aldeias do Xisto, e o reforço do sistema de mobilidade (meios de transporte) do Pinhal Interior.

No âmbito do PRODER (Programa de Desenvolvimento Rural do Continente), o seu eixo 3 pretende dinamizar as áreas rurais, através de duas medidas.

A medida 3.1 ("diversificação da economia e criação de emprego") será concretizada através de acções como a diversificação de actividades na exploração agrícola (mediante actividades económicas de natureza não agrícola, em áreas como o turismo em espaço rural, o turismo de natureza, actividades associadas à caça e pesca em águas interiores, 
entre outras), a criação e o desenvolvimento de micro-empresas (tendo em vista a densificação do tecido económico e a criação de emprego e, deste modo, contribuir para a revitalização económica e social do mundo rural), e o desenvolvimento de actividades turísticas e de lazer (nas componentes de produtos turísticos, nomeadamente ecoturismo, enoturismo, turismo associado a actividades de caça e pesca, turismo equestre, turismo religioso, turismo de saúde, turismo cultural; alojamento turístico de pequena escala nas modalidades de turismo em espaço rural e turismo de natureza; e infra-estruturas de pequena escala, tais como, centros de observação da paisagem, rotas/percursos, animação turística).

A medida 3.2 ("melhoria da qualidade de vida") incluirá acções em dois domínios: a conservação e valorização do património rural (preservação, refuncionalização e valorização da cultura local), e os serviços básicos para a população rural, designadamente os serviços de apoio à infância, o acompanhamento domiciliário a idosos e deficientes, serviços itinerantes de apoio social, e serviços de animação cultural e recreativa de base local.

A implementação deste eixo, segundo a metodologia LEADER, conduzirá, em breve (na sequência da aprovação dos Planos de Desenvolvimento Local, elaborados pelos agentes locais organizados em Grupos de Acção Local), a novas oportunidades para os territórios e as populações/actores rurais (agricultores ou membros do seu agregado familiar, micro-empresas, pessoas singulares ou colectivas de direito privado, autarquias, parcerias privadas, parcerias entre entidades públicas e privadas cuja componente pública não seja maioritária, instituições particulares de solidariedade social e organizações não governamentais), através de apoios concedidos sob a forma de incentivo não reembolsável até uma despesa elegível de 200.000 euros (por projecto). O nível de apoio aos projectos de investimento no quadro da medida 3.1 é variável, de 30 a $60 \%$, de acordo com o montante do investimento total e a criação de postos de trabalho, e no âmbito da medida 3.2 está balizado entre $60 \%$ e $70 \%$ do montante de despesa elegível (sem outro condicionamento).

\section{Conclusão}

O planeamento, reconhecido como ferramenta estruturante do desenvolvimento sustentável e eixo vertebrador dos instrumentos de gestão territorial, assumiu novas dimensões e preocupações, através da 
integração de componentes activas (como a avaliação e a monitorização) e mudanças de atitude no sentido de constituir cada vez mais uma plataforma de convergência de interesses, mediante processos de cooperação, parceria e participação esclarecida de todos os actores e interessados.

No caso da actividade turística, atendendo aos seus efeitos espaciais e ao tipo de recursos envolvidos, as práticas de planeamento e gestão sustentável do turismo são factores de vital importância para a sustentabilidade dos lugares e a viabilidade do turismo.

A maioria dos documentos sobre planeamento e desenvolvimento sustentável do turismo elaborados nos últimos anos reconhece o património natural e cultural como recurso turístico susceptível de traduzir vantagens competitivas para os territórios.

Para aprofundara reflexão sobre o planeamento e o desenvolvimento de novos produtos turísticos ancorados ao património natural e cultural, em territórios de baixa densidade, no contexto das novas escolhas geográficas da oferta/procura turística, das mudanças que marcam o comportamento dos turistas e das tendências evolutivas dos instrumentos relativos à intervenção espacial, utilizámos como referência as Aldeias do Xisto (Pinhal Interior - Centro de Portugal).

Esta intervenção integrada, na amplitude das fases de concepção e implementação (que envolveu dois domínios operativos distintos mas complementares, orientados para as tarefas de infra-estruturação e requalificação dos lugares, e de animação e promoção, respectivamente), apresenta como principais dimensões inovadoras, a valorização dos contextos territoriais e dos recursos endógenos; a criação de uma marca diferenciadora e de um produto turístico original; a construção de uma rede de territórios requalificados e revitalizados; a criação de uma rede de lojas destinadas a comercializar produtos genuínos de qualidade seleccionada; a animação turística e cultural através de uma agenda continuada (oferta ao longo de todo o ano) e diversificada de eventos e actividades de grande qualidade (que decorrem todas as semanas); a comunicação e a difusão de informação, designadamente a revista "Aldeias do Xisto" (em duas fases editoriais distintas) e a plataforma internet (aldeiasdoxisto.pt); a criação de uma rede de caminhos pedestres e centros de BTT; e, finalmente, a gestão e a promoção turística, por via da institucionalização de uma agência para o desenvolvimento turístico das Aldeias do Xisto.

$\mathrm{Na}$ actualidade, a oferta turística e de lazer das Aldeias do Xisto reflecte a importância de quatro dimensões estruturantes: alojamento, 
restauração, artesanato e animação turística; animação; caminhos pedestres e centros de BTT.

As novas janelas de oportunidade para as Aldeias do Xisto, no quadro do novo período de programação e execução das políticas públicas, por sinal mais exigente em matéria de integração, cooperação, parcerias e gestão, como acontece com o PROVERE, fazem da ADXTUR um eixo incontornável em matéria de consolidação e aprofundamento da Rede das Aldeias do Xisto. 